\title{
Novel Potential Biomarkers for Opisthorchis viverrini Infection and Associated Cholangiocarcinoma
}

\author{
NITHIKOON AKSORN ${ }^{1,2}$, SITTIRUK ROYTRAKUL ${ }^{3}$, SUTHATHIP KITTISENACHAI $^{3}$, KAWIN LEELAWAT $^{4}$ \\ PITHI CHANVORACHOTE ${ }^{5}$, SUPACHAI TOPANURAK ${ }^{6}$, SHINJIRO HAMANO ${ }^{7}$ and USA LEK-UTHAI ${ }^{2}$ \\ ${ }^{1}$ Doctor of Public Health Programme (Parasitology), Faculty of Graduate Studies, \\ ${ }^{2}$ Department of Parasitology and Entomology, Faculty of Public Health, and \\ ${ }^{6}$ Department of Molecular Tropical Medicine and Genetics, \\ Faculty of Tropical Medicine, Mahidol University, Bangkok, Thailand; \\ ${ }^{3}$ Proteomics Research Laboratory, National Center for Genetic Engineering and Biotechnology (BIOTEC), \\ Pathum Thani, Thailand; \\ ${ }^{4}$ Department of Surgery, Rajavithi Hospital, Bangkok, Thailand; \\ ${ }^{5}$ Department of Pharmacology and Physiology, Faculty of Pharmaceutical Sciences, \\ Chulalongkorn University, Bangkok, Thailand; \\ ${ }^{7}$ Department of Parasitology, Institute of Tropical Medicine (NEKKEN), \\ Nagasaki, University, Nagasaki, Japan
}

\begin{abstract}
Background/Aim: Early detection of disease is a pivotal factor for determining prognosis and clinical outcome of patients with cancer. As cholangiocarcinoma (CCA) is currently difficult to detect and most cases of such cancer present with late-stage disease at the time of initial diagnosis, we employed proteomic analysis of the bile to identify potential candidate biomarkers for Opisthorchis viverrini (OV)-associated CCA. Materials and Methods: Proteins in pooled bile samples from patients with CCA and $O V$ infection, with CCA without OV infection, with $O V$ infection but no CCA, and with neither $O V$ infection nor CCA were separated by $15 \%$ sodium dodecyl sulfatepolyacrylamide gel electrophoresis, in-gel trypsin digestion and analyzed by liquid chromatography-tandem mass spectrometry. Results: According to our analysis, three proteins, namely aristaless-like homeoboxl isoform X1 (ALX1), major histocompatibility complex polypeptiderelated sequence $A(M I C A)$, and uncharacterized protein C14orf105 isoform X12 were found to be potential markers for $O V$ infection, as they were predominantly found in all
\end{abstract}

This article is freely accessible online.

Correspondence to: Assoc. Prof. Dr. Usa Lek-Uthai, Department of Parasitology and Entomology, Faculty of Public Health, Mahidol University, Bangkok, Thailand. E-mail: usa.lek@mahidol.ac.th

Key Words: Opisthorchis viverrini, cholangiocarcinoma, proteomics, bile, biomarkers.
$O V$-infected groups. Although these proteins were detected in both $O V$-infected patients with and without CCA, their abundance was 2.90-, 7.06-and 3.65-fold higher, respectively, in those with CCA. In patients with CCA, potential novel biomarkers wre immunoglobulin heavy chain, translocated in liposarcoma (TLS), visual system homeobox 2 (VSX2) and an unnamed protein product. Conclusion: We provided novel information regarding potential biomarkers for $O V$ infection and CCA. These two protein profiles could benefit diagnosis as well as monitoring of CCA.

Cholangiocarcinoma (CCA) is a biliary tract malignancy and the second most common primary liver cancer that originates from bile duct epithelial cells (1). Its prevalence varies worldwide, however, the highest incidence of CCA has been recorded in northeastern Thailand, where the prevalence of infection with Opisthorchis viverrini (OV), a human liver fluke, is higher than other regions of the country (2), and it is thought to be an etiology of CCA (3). Chronic OV infection results in a chronic inflammatory state of the bile duct leading to severe hepatobiliary abnormalities (4). Jaundice can occur owing to mechanical obstruction of the biliary tract caused by OV flukes and is also associated with gallstone formation, cholangitis and $\mathrm{CCA}$ as a late complication of chronic infection (5).

Early-stage CCA is difficult to diagnose and most cases of CCA are detected at late stages, too late to be treated by surgery or other methods (6). Ultrasonography, computed tomography (CT) and magnetic resonance imaging (MRI) are used to demonstrate dilatation of the biliary tree due to 
obstruction caused by OV (7). However, these methods have poor sensitivity for diagnosing CCA (8). Cancer antigen 19-9 (CA19-9) and carcino-embryonic antigen (CEA) are markers most often used to follow CCA progression. CA19-9 has a sensitivity of $50-60 \%$ and a specificity of $80 \%$ for diagnosing CCA (9). However, high levels of CEA often are observed in gastrointestinal cancer, especially in colorectal carcinoma (10). Thus, the need to differentiate CCA associated with OV infection from other types of cancer is of importance in order to provide correct diagnosis and appropriate treatment. To that end, bile is a potential source of essential indicators and reflects the alteration of CCA microenvironment found in patients with OV infection as well as CCA.

To our best knowledge, there is no report of biomarkers from human bile samples for OV-associated CCA. Hence, we used proteomic analyses of the bile to identify potential candidate biomarkers for OV-associated CCA. These data should be useful for the development of diagnostic tools for early detection and monitoring of CCA patients with OV infection.

\section{Materials and Methods}

Study subjects and collection of bile samples. Bile samples were collected from patients with obstructive jaundice undergoing endoscopic retrograde cholangiopancreatography at the Department of Surgery, Rajavithi Hospital, Bangkok and Department of Diagnostic Radiology, Udon Thani Cancer Hospital, Udon Thani province and had surgery performed at the Department of Surgery, Udon Thani Cancer Hospital, Udon Thani Province, Thailand, during March 2014 to January 2016. Of the 43 individuals with obstructive jaundice, 28 also had CCA diagnosed by clinical, ultrasound, CT scan and biopsy, and 15 did not have CCA (13 with bile duct stones and two with cholangitis).

Bile samples from CCA and non-CCA patients were divided into four groups based on the presence of OV infection by detection using real-time polymerase chain reaction. The amplification of genomic DNA of OV was carried out using the following primers: forward primer 5'-CAT AAG GTT GAC TAG GAA ACC GGG-3' (position 97-120) and reverse primer 5'-TGT TCT CAG GCA AGT GAG TGT GCT-3' (position 288-310). The primers were designed to amplify a repetitive DNA fragment specific for OV which showed no significant homology to DNA from other parasites (Aksorn et al., unpublished data).

Aliquots of 5- to 10-ml of bile samples were collected from each study participant and the samples were stored at $-80^{\circ} \mathrm{C}$ until analysis.

The study was approved by the Ethics Committee on Research involving Human Subjects, Rajavithi Hospital (N0.051/2557) and the Ethics Committee on Human Research, Udon Thani Cancer Hospital (N0.4/2557). All participants provided prior written informed consent.

Sample preparation, sodium dodecyl sulfate polyacrylamide gel electrophoresis (SDS-PAGE) and tryptic digestion. Bile protein concentration was determined by Lowry's method using bovine serum albumin (BSA) as protein standard. An equal amount of pooled bile protein from each group ( $50 \mu \mathrm{g}$ each) was separated by $15 \%$ SDS-PAGE followed by silver staining (11). The stained gel was scanned using a GS-710 scanner (Bio-Rad, Hercules, CA, USA) before being stored in $0.1 \%(\mathrm{v} / \mathrm{v})$ acetic acid. The gel was then sliced into 14 pieces per lane and each piece further cut into smaller pieces $\left(1 \mathrm{~mm}^{3} /\right.$ piece $)$, placed into a gel plug, dehydrated with $100 \%$ acetonitrile $(\mathrm{ACN})$ for $5 \mathrm{~min}$, dried at room temperature for $15 \mathrm{~min}$, then was added to $10 \mathrm{mM}$ ammonium bicarbonate $\left(\mathrm{NH}_{4} \mathrm{HCO}_{3}\right)$ containing $10 \mathrm{mM}$ dithiothreitol for 1 hour at room temperature and alkylated with $100 \mathrm{mM}$ iodoacetamide in $10 \mathrm{mM}$ $\mathrm{NH}_{4} \mathrm{HCO}_{3}$ for $1 \mathrm{~h}$ in the dark. The gel pieces were dehydrated twice in $100 \% \mathrm{ACN}$ for $5 \mathrm{~min}$ each time and then incubated with $10 \mu \mathrm{l}$ of trypsin solution $(10 \mathrm{ng} / \mu \mathrm{l}$ trypsin in $50 \% \mathrm{ACN}$ in $10 \mathrm{mM}$ $\mathrm{NH}_{4} \mathrm{HCO}_{3}$ ) for $20 \mathrm{~min}$ at room temperature. A $20 \mu \mathrm{l}$ aliquot of $30 \%$ ACN was added to keep the gel immersed and it was incubated overnight at room temperature. The trypsiniszed peptides were subsequently extracted from the gel three times with $30 \mu \mathrm{l}$ of $50 \%$ $\mathrm{ACN}$ in $0.1 \%$ formic acid. Finally, the peptide mixture was dried and kept at $-80^{\circ} \mathrm{C}$ prior to analysis by liquid chromatographytandem mass spectrometry (LC-MS/MS).

LC/MS-MS analysis. LC/MS-MS for protein quantitation and identification was conducted using the HCTultra PTM Discovery System (Bruker Daltonics, Bremen, Germany) coupled to an UltiMate 3000 LC System (Dionex, Sunnyvale, CA, USA). Peptides were separated on a nanocolumn (PepSwift monolithic column $100 \mu \mathrm{m}$ i.d. $\times 50 \mathrm{~mm}$ ). Eluent A was $0.1 \%$ formic acid and eluent B was $80 \%$ ACN in water containing $0.1 \%$ formic acid. Peptide separation was achieved with a linear gradient from $10 \%$ to $70 \%$ of eluent B for $13 \mathrm{~min}$ at a flow rate of $300 \mathrm{nl} / \mathrm{min}$, including a regeneration and an equilibration step at $90 \%$ and $10 \%$ eluent B, respectively. Peptide fragment mass spectra were acquired in a data-dependent AutoMS with a scan range of $300-1500 \mathrm{~m} / \mathrm{z}$. Three averages, and up to five precursor ions were selected from the MS scan 50-3000 m/z. MS/MS analysis of peptides generated the spectral data for further protein identification against database search.

Data and bioinformatics analyses. MS/MS data were analyzed using DeCyder MS (GE Healthcare, Piscataway, NJ, USA) and submitted to a search employing Mascot software (Matrix Science, London, UK) of the National Center for Biotechnology Information database for protein identification. Database interrogation was for taxonomy (Homo sapiens), enzyme (trypsin), variable modifications (carbamidomethyl, oxidation of methionine residues), mass values (monoisotopic), protein mass (unrestricted), peptide mass tolerance (1 Da), fragment mass tolerance $( \pm 0.4 \mathrm{Da})$, peptide charge state $(1+$, $2+$ and $3+)$, and mass missed cleavages. For identification, each protein was required to have at least one peptide with an individual mascot score corresponding to a $p$-value of less than 0.05 . In order to determine an appropriate statistical method to assess the differential abundance of proteins, protein fold-changes among the groups were computed using a comparison of the averaged $\log 2$ fold change between two groups, e.g. $\log 2$ fold-change $=\log 2$ $(\mathrm{CCA}+\mathrm{OV}+)-\log 2 \quad(\mathrm{CCA}+\mathrm{OV}-)$. Functional interaction and association among the identified proteins were examined using the precomputed database STITCH Version 5.0 (http://stitch.embl.de/).

\section{Results}

OV status and SDS-PAGE analysis of bile proteins. Among 28 CCA cases, seven cases were positive for OV DNA $(\mathrm{CCA}+\mathrm{OV}+)$ and 21 were $\mathrm{OV}$ DNA-negative (CCA+OV-), 
and among 15 non-CCA cases, six were OV DNA-positive $(\mathrm{CCA}-\mathrm{OV}+)$ and nine were OV DNA-negative (CCA-OV-).

As bile may reflect alteration of protein profile found in close proximity to CCA, preliminary assays were carried out to elucidate the bile protein pattern from patients with CCA with and without $\mathrm{OV}$ infection in comparison to those who were cancer-free with and without OV infection. Bile samples were pooled before being separated by $15 \%$ SDSPAGE to reduce variation among individual samples and to minimize data in the subsequent bioinformatics analysis Protein sizes ranged from 14 to $97 \mathrm{kDa}$. The gel was divided into 14 slices (Figure 1). For example, the protein bands in slices 4 and 7 were dominant in $\mathrm{CCA}+$ $(\mathrm{CCA}+\mathrm{OV}+$ and $\mathrm{CCA}+\mathrm{OV}-)$ groups. However, the protein bands in slice 6 were more intense in $\mathrm{CCA}-(\mathrm{CCA}-\mathrm{OV}+$ and $\mathrm{CCA}-\mathrm{OV}-$ ) groups.

Bile proteomic profiling. Using a proteomics approach, a total of 938 proteins were identified from the four groups of bile samples, with $905,878,875$ and 890 proteins present in $\mathrm{CCA}+\mathrm{OV}+, \quad \mathrm{CCA}+\mathrm{OV}-, \quad \mathrm{CCA}-\mathrm{OV}+$ and $\mathrm{CCA}-\mathrm{OV}-$ samples, respectively. A Venn diagram of proteins common among the four bile groups revealed three proteins to be present in both $\mathrm{CCA}+\mathrm{OV}+$ and $\mathrm{CCA}-\mathrm{OV}+$ groups, and four proteins in both $\mathrm{CCA}+\mathrm{OV}+$ and $\mathrm{CCA}+\mathrm{OV}-$ groups (Figure 2 ). It is worth noting that there was no single protein unique to each bile group.

Candidate biomarkers for OV infection. Three proteins found in quantitatively significant amounts in both $\mathrm{CCA}+\mathrm{OV}+$ and $\mathrm{CCA}-\mathrm{OV}+$ but not in other groups were demonstrated as candidate protein markers of $\mathrm{OV}$ infection. The three proteins were aristaless-like homeobox1 isoform X1 (ALX1; gil530400865), major histocompatibility complex polypeptide-related sequence A (MICA), (gil1764074) and uncharacterized protein C14orf105 isoform X12 (gil578825929) (Figure 2). Their levels were 2.90-, 7.06-and 3.65 -fold higher, respectively, in $\mathrm{CCA}+\mathrm{OV}+$ than in $\mathrm{CCA}-$ $\mathrm{OV}+($ Table I).

Candidate biomarkers for CCA. Four proteins demonstrated as candidates found in both $\mathrm{CCA}+\mathrm{OV}+$ and $\mathrm{CCA}+\mathrm{OV}-$ but not in other groups were immunoglobulin ( $\mathrm{Ig}$ ) heavy chain (gil4753744), translocated in liposarcoma (TLS; il448295), visual system homeobox 2 (VSX2; gil34365783), and an unnamed protein product (gil194378026) (Figure 2). Their levels were 4.76-, 4.79-, 2.67-and 3.19-fold higher, respectively, in $\mathrm{CCA}+\mathrm{OV}+$ than those in $\mathrm{CCA}+\mathrm{OV}-($ Table I).

Interaction map for the identified candidate marker proteins. STITCH Version 5.0 (http://stitch.embl.de/) was employed to identify binding partners for TLS, VSX2, ALX1 and MICA to identify binding partners and generate a protein interaction
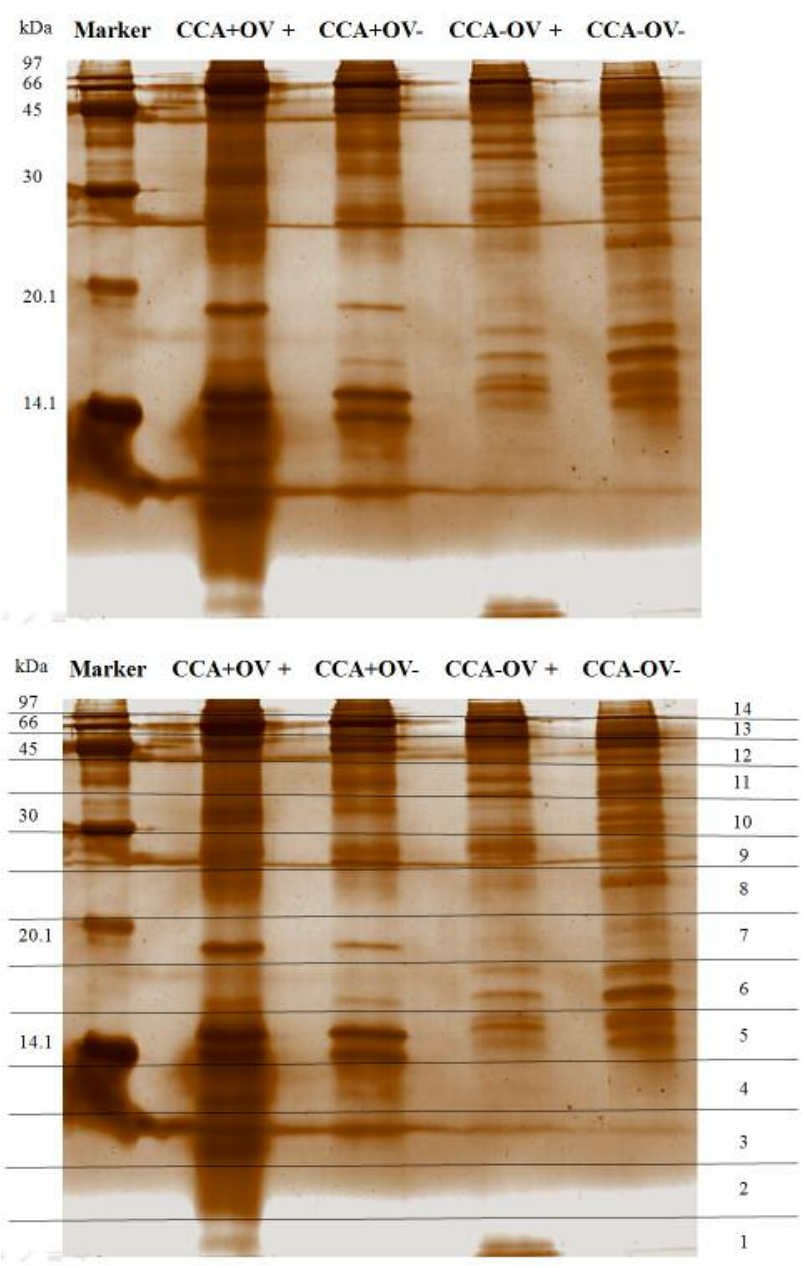

Figure 1. Silver-stained gel of crude bile proteins from different patient groups. Protein were separated by $15 \%$ sodium dodecyl sulfatepolyacrylamide gel electrophoresis. Pooled crude bile (50 $\mu \mathrm{g})$ were loaded in each lane. Lane marker, standard molecular mass markers $(k D a)$. CCA: Cholangiocarcinoma; OV: Opisthorchis viverrini infection; $+:$ with; -: without. Numbers in right margin indicate the 14 gel slices used for subsequent trypsin digestion and liquid chromatographytandem mass spectrometry analysis.

network. Ig heavy chain, unnamed protein product and uncharacterized protein C14orf105 isoform X12 were not present in the map as they are not included (as expected) in the STITCH database. The map revealed involvement of two out of the four candidate proteins in the interactions of the following factors relevant to CCA tumorigenesis: Epidermal growth factor receptor (EGFR), interferon beta 1 fibroblast (IFNB1), Kirsten rat sarcoma (KRAS), mucin 1 (MUC1), mucin 5AC (MUC5AC), and tumor protein p53 (TP53); and with anticancer drugs: doxorubicin, cisplatin, gemcitabine, 5fluorouracil, capecitabine, docetaxel, irinotecan, and leucovorin (Figure 3). 


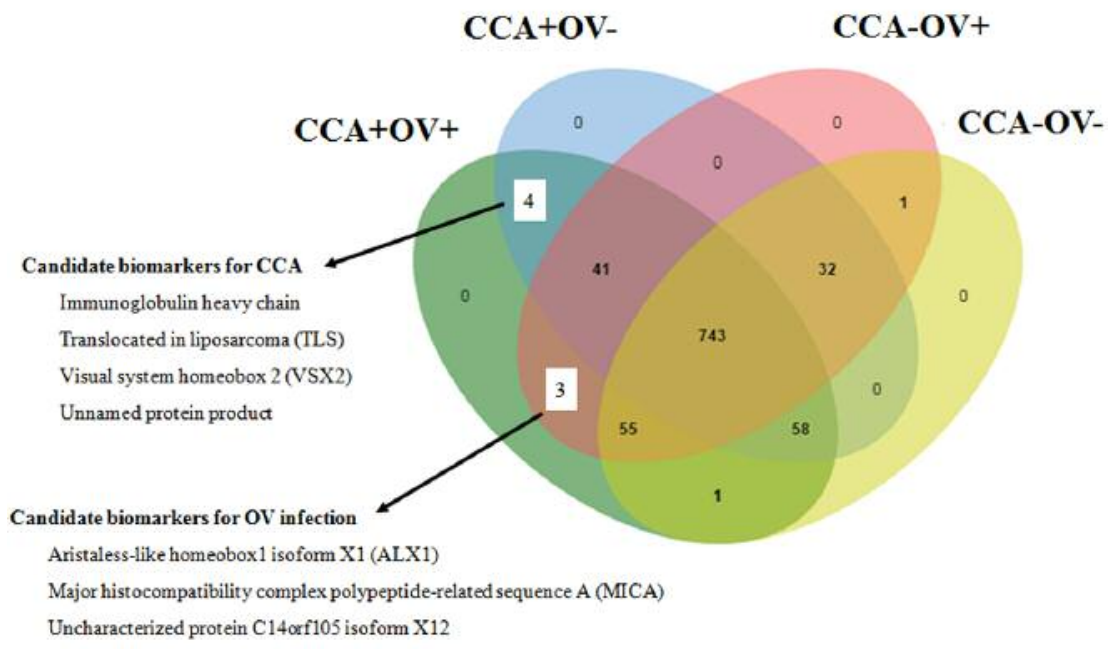

Figure 2. Venn diagram of proteomes of bile from patients with (+) and without (-) cholangiocarcinoma (CCA) and Opisthorchis viverrini (OV) infection. Numbers indicate the number of proteins of interest.

\section{Discussion}

CCA is a tumor arising from epithelial cells of the intrahepatic or extrahepatic bile ducts (12). Endemic areas for liver fluke infection, such as Thailand and China (13), are also the regions with the highest worldwide incidence of both intrahepatic and extrahepatic CCA. The parasite persists over years and progressively accumulates in the biliary system causing an inflammatory response and an increased risk of CCA (14). Chronic inflammation and biliary duct cell injury induced by the obstruction of bile flow are two of the main conditions responsible for the development of CCA (15). In CCA with bile duct obstruction, biliary drainage is introduced to reduce complications (16). Bile sampling represents a possible opportunity to detect changes in the CCA microenvironment, to understand the molecular and biochemical mechanisms that drive CCA tumor initiation, maintenance and progression (17, 18). The bile obtained from patients with biliary obstruction is more likely to contain higher concentrations of CCA-associated proteins than serum and, thus, represents an alternative fluid for identifying potential biomarkers of CCA (19).

Improvement in early detection of cancer is accepted as a key to increase the survival rate of patients with cancer. Advances in technology have provided important and precise tools for disease-specific biomarkers. Proteomics offers an unprecedented opportunity for identifying new biomarkers and therapeutic targets and providing an understanding of the biochemical pathways involved in pathogenesis (20). Using a shotgun proteomic approach, Kristiansen et al. (21) identified several cancer-associated proteins in bile samples obtained from patients with CCA, and Shen et al. (22) identified spermatogenesis-associated protein 20 (SSP411) in individual bile samples from patients with CCA. SSP411 was also demonstrated as a novel serum diagnostic biomarker for CCA by enzyme-linked immunosorbent assay and receiver operating characteristic analysis. Related studies have identified additional biomarkers for CCA from plasma. Khoontawad et al. identified exostosin 1 (EXT1) at a level in the plasma that might be involved in CCA genesis and might be a potential biomarker of CCA (23). Rucksaken et al. identified orosomucoid 2 (ORM2) and kinesin family member 18A (KIF18A) in plasma samples as potential biomarkers for early diagnosis of CCA (24). For OV-associated CCA, Yonglitthipagon et al. (25) applied a proteomics-based approach to find differentially expressed tumor proteins in CCA cell lines. They suggested that up-regulation of annexin A2 (ANXA2) may serve as a prognostic marker for invasion, metastasis and survival in OV-associated CCA (25). In addition, these authors extended their analyses to include a computational analysis of the promoter regions of the proliferation-associated genes. Likewise, the detection of somatic and rare germline mutations has been shown to be a promising tool for understanding the biology and clinical importance of mutation profiles in gallbladder carcinoma (26).

We used the technique of pooling bile samples before proteomic analysis to reduce the variation among individual samples and minimize the data files subjected to bioinformatics analysis. The advantages of pooling are increased analytical efficiency, with cost and time savings (27). Even though the presence of higher abundance proteins such as albumin may mask the detection of lower abundance proteins, removal of albumin may also lead to loss of other low abundance proteins, such as small molecular weight cytokines, molecules that may act as biomarkers (28). Therefore, the total proteins in the present study were retrieved from the crude bile without depletion of high 


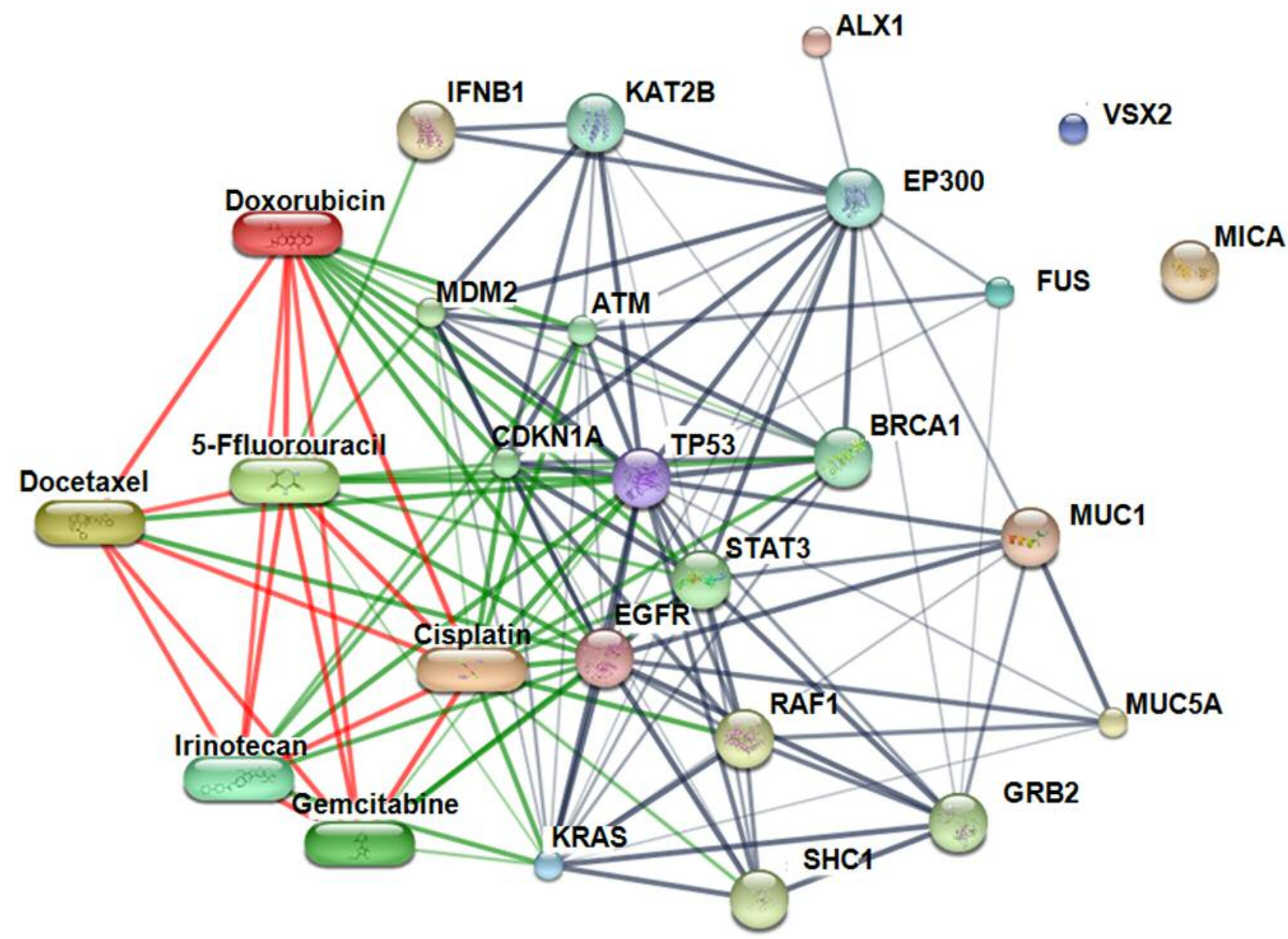

Figure 3. Protein-chemical interaction network constructed using the STITCH software incorporating candidate protein biomarkers candidate protein markers. ALX1: Aristaless-like homeobox1 isoform X1; TLS: translocated in liposarcoma; VSX2: visual system homeobox 2; FUS: fused in sarcoma; MICA: major histocompatibility complex polypeptide-related sequence A; KRAS: Kirsten rat sarcoma viral oncogene homolog; EGFR: epidermal growth factor receptor; TP53: tumor protein p53; MUC1: mucin 1; MUC5AC: mucin 5A; IFNB1: Interferon, beta 1, fibroblast; SHC1: Src homology 2 domaincontaining transforming protein 1; ATM: ataxia telangiectasia mutated; BRCA1: breast cancer 1; CDKN1A: cyclin-dependent kinase inhibitor 1A; EP300: E1A binding protein p300; GRB2: growth factor receptor-bound protein 2; STAT3: signal transducer and activator of transcription 3; MDM2: p53 E3 ubiquitin protein ligase homolog; RAF1: v-raf-1 murine leukemia viral oncogene homolog 1.

abundant proteins such albumin. Figure 1 indicates that protein pattern detectable by SDS-PAGE markedly differed among the four groups. Differences between the electrophoretic patterns indicated that cholangiocytes respond to liver fluke infection and development of CCA differently.

Biomarkers were identified based on identifying proteins with expression that differed between the four groups. For candidate proteins for OV infection, ALX1, MICA, and uncharacterized protein $\mathrm{C} 14$ orf105 isoform X12 were found in both $\mathrm{CCA}+\mathrm{OV}+$ and $\mathrm{CCA}-\mathrm{OV}+$, but not in other groups. ALX1 plays a role in neuronal and craniofacial development (29). More recently, ALX1 was also shown to regulate the expression of genes that induce epithelial-to-mesenchymal transition in primary mesenchyme cells and to play a key role in tumor progression and metastasis (30-33). However, little is known about ALX1 function in OV infection. MICA is significantly elevated with increasing cancer stage and metastasis (34). There are a number of studies on the role of MICA in relation to the presence of infectious agents, such viruses, bacteria and parasites. For example, a high level of MICA polymorphisms correlates with advanced liver fibrosis in Schistosoma japonicum infection (35). In addition, it is associated with susceptibility or progression of several infectious diseases such as dengue fever (36), tuberculosis (37) and Chagas disease (38). Currently, no data are available regarding MICA and OV infection as far as we are aware.

The proteins found in both $\mathrm{CCA}+\mathrm{OV}+$ and $\mathrm{CCA}+\mathrm{OV}-$ groups as candidate markers of CCA included immunoglobulin 
Table I. Quantification of selected proteins.

\begin{tabular}{|c|c|c|c|c|c|}
\hline Candidate protein markers for & Protein name & $\begin{array}{l}\text { Accession } \\
\text { number }\end{array}$ & $\begin{array}{l}\text { Peptide } \\
\text { sequence }^{b}\end{array}$ & $\begin{array}{c}\text { Protein } \\
\text { score }^{\mathrm{c}}\end{array}$ & Fold-changed \\
\hline \multirow[t]{3}{*}{ Opisthorchis viverrini infection } & $\begin{array}{l}\text { Aristaless-like homeobox } 1 \\
\text { isoform X1 }\end{array}$ & gil530400865 & KRERYGQIQQAK & 15.71 & 2.9 \\
\hline & $\begin{array}{l}\text { Major histocompatibility complex } \\
\text { polypeptide-related sequence A }\end{array}$ & gil1764074 & KTSAA & 1.27 & 7.06 \\
\hline & $\begin{array}{c}\text { Uncharacterized protein C14orf105 } \\
\text { isoform X12 }\end{array}$ & gil578825929 & GPAPK & 6.17 & 3.65 \\
\hline \multirow[t]{4}{*}{ Cholangiocarcinoma } & $\begin{array}{l}\text { Immunoglobulin } \\
\text { heavy chain }\end{array}$ & gil4753744 & $\begin{array}{l}\text { LLESGAEVKKPG } \\
\text { SSVMVSCK }\end{array}$ & 10.2 & 4.76 \\
\hline & $\begin{array}{l}\text { Translocated in } \\
\text { liposarcoma }\end{array}$ & gil448295 & $\begin{array}{l}\text { GGPMGEGGYGG } \\
\text { GGSGGGGR }\end{array}$ & 14.53 & 4.79 \\
\hline & $\begin{array}{l}\text { Visual system } \\
\text { homeobox } 2\end{array}$ & gil34365783 & SLEAAAESGR & 27.67 & 2.67 \\
\hline & $\begin{array}{l}\text { Unnamed protein } \\
\text { product }\end{array}$ & gil194378026 & TVALFFFF & 13.94 & 3.19 \\
\hline
\end{tabular}

aUnique identifier for the protein according to DeCyder MS (GE Healthcare, Piscataway, NJ, USA). bFrom Mascot software database used as the reference proteome. ${ }^{\mathrm{C}}$ Goodness-of-fit between the observed tandem mass spectrometric spectrum and the theoretical spectrum of the proposed peptide. ${ }^{\mathrm{d}}$ Comparison of the averaged $\log 2$ fold-change between two groups.

Ig heavy chain, TLS, VSX2 and an unnamed protein product. Studies showed an association between Ig and other cancer types. IgG produced in lung cancer is believed to play a key role in cancer growth and metastasis, with significant clinical implications (39). $\operatorname{IgA}, \operatorname{IgE}$ and $\operatorname{IgG}$ have been reported in serum and bile samples of patients with opisthorchiasis (40). In this study, the proteomic data did not identify the class of immunoglobulin and further study will be needed to identify the class of Ig heavy chain associated with CCA. TLS is a functional protein-associated transcription factor which fusesto a heterologous DNA-binding protein, Ewing's sarcoma (EWS) or TATA-binding protein-associated factor 15 (TAF15). TLS has potent transcriptional activation domains, forming abnormal transcriptional factors that induce malignant tumor development $(41,42)$. Recently, TLS was found to be associated with neurodegenerative diseases, such as amyotrophic lateral sclerosis and frontotemporal lobar degeneration $(43,44)$. VSX2 is thought to act principally as a repressor of transcription, particularly of genes encoding cyclin-dependent kinase inhibitor $\left(\mathrm{p} 27^{\mathrm{KIP} 1}\right)$ and microphthalmia transcription factor (MITF) (45). VSX2 gene was most specific at identifying those at risk of colorectal cancer, with a sensitivity of $83 \%$ and a specificity of $92 \%$ (46).

Various chemotherapeutic agents, either alone or in combination, have been tested against CCA (47). In this study, STITCH, Version 5.0 was employed to identify binding partners for the proteins identified and generate a protein interaction network. It is worth noting that cisplatin, docetaxel, doxorubicin, 5-fluorouracil, gemcitabine, and irinotecan directly bind TP53, well known as the 'guardian of the genome' (48), with which both ALX1 and TLS interact, although indirectly.

This study, through application of SDS-PAGE and subsequent identification of bile proteins by means of LCMS/MS, reports the discovery of potential candidate biomarkers ALX1 (gil530400865), MICA, uncharacterized protein $\mathrm{C} 14$ orf 105 isoform X12 for OV and Ig heavy chain, TLS, VSX2, and an unnamed protein product (gil194378026)) for CCA. The protein interaction map further reveals indirect interaction of ALX1 and TLS with tumor protein $\mathrm{p} 53$, is the target of a number of anticancer drugs. Further studies are required to validate the potential of these protein sets as biomarkers for their respective disease, and find the means to capitalize the information gleaned from the protein interaction network.

\section{Conflicts of Interest}

The Authors declare that there exists no conflict of interest in regard to this research.

\section{Acknowledgements}

This research was supported by a Royal Golden Jubilee (RGJ) Ph.D. Program scholarship from The Thailand Research Fund (grant no. PHD/0313/2552;RGJ 12) and also in part by the China Medical Board, Faculty of Public Health, Mahidol University. The Authors thank Dr. Jerasak Wannaprasert, Department of Surgery, Rajavithi Hospital, and Dr. Sundusit Pengsa, Department of Surgery and Dr. Namthip Munponsri, Department of Diagnostic Radiology, Udon Thani Cancer Hospital, Udon Thani Province, for bile sample collection. The Authors also thank Professor Dr. Prapon Wilairat for editing the manuscript and the valuable comments provided. 


\section{References}

1 Everhart JE and Ruhl CE: Burden of digestive diseases in the United States part III: liver, biliary tract, and pancreas. Gastroenterology 136(4): 1134-1144, 2009.

2 Srivatanakul P: Epidemiology of liver cancer in Thailand. Asian Pac J Cancer Prev 2(2): 117-121, 2001.

3 Sripa B and Pairojkul C: Cholangiocarcinoma: lessons from Thailand. Curr Opin Gastroenterol 24(3): 349-356, 2008.

4 Sripa B, Kaewkes S, Sithithaworn P, Mairiang E, Laha T, Smout M, Pairojkul C, Bhudhisawasdi V, Tesana S, Thinkamrop B, Bethony JM, Loukas A and Brindley PJ: Liver fluke induces cholangiocarcinoma. PLoS Med 4(7): e201, 2007.

5 Lim JH: Liver flukes: the malady neglected. Korean J Radiol 12(3): 269-279, 2011.

6 Blechacz B and Gores GJ: Cholangiocarcinoma: advances in pathogenesis, diagnosis, and treatment. Hepatology 48(1): 308321,2008

7 el Sheikh Mohamed AR, al Karawi MA and Yasawy MI: Modern techniques in the diagnosis and treatment of gastrointestinal and biliary tree parasites. Hepatogastroenterology 38(2): 180-188, 1991.

8 Nguyen K and Sing JT Jr.: Review of endoscopic techniques in the diagnosis and management of cholangiocarcinoma. World $\mathrm{J}$ Gastroenterol 14(19): 2995-2999, 2008.

9 Nehls O, Gregor M and Klump B: Serum and bile markers for cholangiocarcinoma. Semin Liver Dis 24(2): 139-154, 2004.

10 Van Beers BE: Diagnosis of cholangiocarcinoma. HPB (Oxford) 10(2): 87-93, 2008

11 Blum H, Beier H and Gross HJ: Improved silver staining of plant proteins, RNA and DNA in polyacrylamide gels. Electrophoresis 8: 93-99, 1987.

12 Esposito $I$ and Schirmacher P: Pathological aspects of cholangiocarcinoma. HPB (Oxford) 10(2): 83-86, 2008.

13 Parkin DM: The global health burden of infection-associated cancers in the year 2002. Int J Cancer 118(12): 3030-3044, 2006.

14 Haswell-Elkins MR, Sithithaworn P, Mairiang E, Elkins DB, Wongratanacheewin S, Kaewkes S and Mairiang P: Immune responsiveness and parasite-specific antibody levels in human hepatobiliary disease associated with Opisthorchis viverrini infection. Clin Exp Immunol 84(2): 213-218, 1991.

15 Lazaridis KN and Gores GJ: Cholangiocarcinoma. Gastroenterology 128(6): 1655-1667, 2005.

16 Paik WH, Loganathan $\mathrm{N}$ and Hwang JH: Preoperative biliary drainage in hilar cholangiocarcinoma: When and how? World $\mathrm{J}$ Gastrointest Endosc 6(3): 68-73, 2014.

17 Wang Y, Yamaguchi Y, Watanabe H, Ohtsubo K, Wakabayashi T and Sawabu N: Usefulness of $p 53$ gene mutations in the supernatant of bile for diagnosis of biliary tract carcinoma: comparison with $K$ RAS mutation. J Gastroenterol 37(10): 831-839, 2002.

18 Bonney GK, Craven RA, Prasad R, Melcher AF, Selby PJ and Banks RE: Circulating markers of biliary malignancy: opportunities in proteomics? Lancet Oncol 9(2): 149-158, 2008.

19 Farina A, Dumonceau JM and Lescuyer P: Proteomic analysis of human bile and potential applications for cancer diagnosis. Expert Rev Proteomics 6(3): 285-301, 2009.

20 Srinivas PR, Srivastava S, Hanash S and Wright GL Jr.: Proteomics in early detection of cancer. Clin Chem 47(10): 1901-1911, 2001.

21 Kristiansen TZ, Bunkenborg J, Gronborg M, Molina H, Thuluvath PJ, Argani P, Goggins MG, Maitra A and Pandey A: A proteomic analysis of human bile. Mol Cell Proteomics 3(7): 715-728, 2004.
22 Shen J, Wang W, Wu J, Feng B, Chen W, Wang M, Tang J, Wang F, Cheng F, Pu L, Tang Q, Wang X and Li X: Comparative proteomic profiling of human bile reveals SSP411 as a novel biomarker of cholangiocarcinoma. PLoS One 7(10): e47476, 2012.

23 Khoontawad J, Hongsrichan N, Chamgramol Y, Pinlaor P, Wongkham C, Yongvanit P, Pairojkul C, Khuntikeo N, Roytrakul $\mathrm{S}$, Boonmars $\mathrm{T}$ and Pinlaor S: Increase of exostosin 1 in plasma as a potential biomarker for opisthorchiasis-associated cholangiocarcinoma. Tumour Biol 35(2): 1029-1039, 2014.

24 Rucksaken R, Khoontawad J, Roytrakul S, Pinlaor P, Hiraku Y, Wongkham C, Pairojkul C, Boonmars $\mathrm{T}$ and Pinlaor S: Proteomic analysis to identify plasma orosomucoid 2 and kinesin $18 \mathrm{~A}$ as potential biomarkers of cholangiocarcinoma. Cancer Biomark 12(2): 81-95, 2012.

25 Yonglitthipagon P, Pairojkul C, Chamgramol Y, Mulvenna J and Sripa B: Up-regulation of annexin A2 in cholangiocarcinoma caused by Opisthorchis viverrini and its implication as a prognostic marker. Int J Parasitol 40(10): 1203-1212, 2010.

26 Yadav S, DE Sarkar N, Kumari N, Krishnani N, Kumar A and Mittal B: Targeted gene sequencing of gallbladder carcinoma identifies high-impact somatic and rare germline mutations. Cancer Genomics Proteomics 14(6):495-506, 2017.

27 Diz AP, Truebano M and Skibinski DO: The consequences of sample pooling in proteomics: an empirical study. Electrophoresis 30(17): 2967-2975, 2009.

28 Granger J, Siddiqui J, Copeland S and Remick D: Albumin depletion of human plasma also removes low abundance proteins including the cytokines. Proteomics 5(18): 4713-4718, 2005.

29 Uz E, Alanay Y, Aktas D, Vargel I, Gucer S, Tuncbilek G, von Eggeling F, Yilmaz E, Deren O, Posorski N, Ozdag H, Liehr T, Balci S, Alikasifoglu M, Wollnik B and Akarsu NA: Disruption of ALX1 causes extreme microphthalmia and severe facial clefting: expanding the spectrum of autosomal-recessive ALX-related frontonasal dysplasia. Am J Hum Genet 86(5): 789-796, 2010.

30 Yuan H, Kajiyama H, Ito S, Yoshikawa N, Hyodo T, Asano E, Hasegawa H, Maeda M, Shibata K, Hamaguchi M, Kikkawa F and Senga T: ALX1 induces snail expression to promote epithelial-to-mesenchymal transition and invasion of ovarian cancer cells. Cancer Res 73(5): 1581-1590, 2013.

31 Yang M, Pan Y and Zhou Y: Depletion of ALX1 causes inhibition of migration and induction of apoptosis in human osteosarcoma. Tumour Biol 36(8): 5965-5970, 2015.

$32 \mathrm{Wu}$ SY, Yang YP and McClay DR: TWIST is an essential regulator of the skeletogenic gene regulatory network in the sea urchin embryo. Dev Biol 319(2): 406-415, 2008.

33 Yao W, Liu Y, Zhang Z, Li G, Xu X, Zou K, Xu Y and Zou L: ALX1 promotes migration and invasion of lung cancer cells through increasing SNAIL expression. Int J Clin Exp Pathol 8(10): 12129-12139, 2015.

34 Holdenrieder S, Stieber P, Peterfi A, Nagel D, Steinle A and Salih HR: Soluble MICA in malignant diseases. Int J Cancer 118(3): 684-687, 2006.

35 Gong Z, Luo QZ, Lin L, Su YP, Peng HB, Du K, Yu P and Wang SP: Association of MICA gene polymorphisms with liver fibrosis in schistosomiasis patients in the Dongting Lake region. Braz J Med Biol Res 45(3): 222-229, 2012.

36 García G, del Puerto F, Pérez AB, Sierra B, Aguirre E, Kikuchi M, Sánchez L, Hirayama K, and Guzmán MG: Association of MICA and MICB alleles with symptomatic dengue infection. Hum Immunol 72(10): 904-907, 2011. 
37 Souza CF, Noguti EN, Visentainer JE, Cardoso RF, Petzl-Erler ML and Tsuneto LT: HLA and MICA genes in patients with tuberculosis in Brazil. Tissue Antigens 79(1): 58-63, 2012.

38 Ayo CM, Oliveira AP, Camargo AV, Mattos CC, Bestetti RB and Mattos LC: Association of the functional MICA-129 polymorphism with the severity of chronic Chagas heart disease. Clin Infect Dis 61(8): 1310-1313, 2015.

39 Jiang C, Huang T, Wang Y, Huang G, Wan X and Gu J: Immunoglobulin $\mathrm{G}$ expression in lung cancer and its effects on metastasis. PLoS One 9(5): e97359, 2014.

40 Wongratanacheewin S, Bunnag D, Vaeusorn N and Sirisinha S: Characterization of humoral immune response in the serum and bile of patients with opisthorchiasis and its application in immunodiagnosis. Am J Trop Med Hyg 38(2): 356-362, 1988.

41 Prasad DD, Ouchida M, Lee L, Rao VN and Reddy ES: TLS/FUS fusion domain of TLS/FUS-ERG chimeric protein resulting from the $\mathrm{t}(16 ; 21)$ chromosomal translocation in human myeloid leukemia functions as a transcriptional activation domain. Oncogene 9(12): 3717-3729, 1994.

42 Bertolotti A, Bell B and Tora L: The $N$-terminal domain of human TAFII68 displays transactivation and oncogenic properties. Oncogene 18(56): 8000-8010, 1999.

43 Kwiatkowski TJ Jr., Bosco DA, Leclerc AL, Tamrazian E, Vanderburg CR, Russ C, Davis A, Gilchrist J, Kasarskis EJ, Munsat T, Valdmanis P, Rouleau GA, Hosler BA, Cortelli P, de Jong PJ, Yoshinaga Y, Haines JL, Pericak-Vance MA, Yan J, Ticozzi N, Siddique T, McKenna-Yasek D, Sapp PC, Horvitz HR, Landers JE and Brown RH Jr.: Mutations in the FUS/TLS gene on chromosome 16 cause familial amyotrophic lateral sclerosis. Science 323(5918): 1205-1208, 2009.
44 Vance C, Rogelj B, Hortobágyi T, De Vos KJ, Nishimura AL, Sreedharan J, Hu X, Smith B, Ruddy D, Wright P, Ganesalingam J, Williams KL, Tripathi V, Al-Saraj S, Al-Chalabi A, Leigh PN, Blair IP, Nicholson G, de Belleroche J, Gallo JM, Miller CC and Shaw CE: Mutations in FUS, an RNA processing protein, cause familial amyotrophic lateral sclerosis type 6. Science 323(5918): 1208-1211, 2009.

45 Liang L and Sandell JH: Focus on molecules: homeobox protein CHX10. Exp Eye Res 86(4): 541-542, 2008.

46 Mori Y, Olaru AV, Cheng Y, Agarwal R, Yang J, Luvsanjav D, Yu W, Selaru FM, Hutfless S, Lazarev M, Kwon JH, Brant SR, Marohn MR, Hutcheon DF, Duncan MD, Goel A and Meltzer SJ: Novel candidate colorectal cancer biomarkers identified by methylation microarray-based scanning. Endocr Relat Cancer 18(4): 465-478, 2011.

47 Ramírez-Merino N, Aix SP and Cortés-Funes H: Chemotherapy for cholangiocarcinoma: An update. World J Gastrointest Oncol 5(7): 171-176, 2013.

48 Lane DP: Cancer. p53, guardian of the genome. Nature 358(6381): 15-16, 1992
Received March 14, 2018

Revised April 11, 2018

Accepted April 13, 2018 